\section{MEETING ROUND-UP}

W

ith conference season upon us and the 2015 British Dental Conference \& Exhibition due to take place in Manchester from 7-9 May 2015, we are taking this opportunity to highlight some recent meetings featuring young dentists and students which have taken place around the country:

Undergraduate research in the spotlight

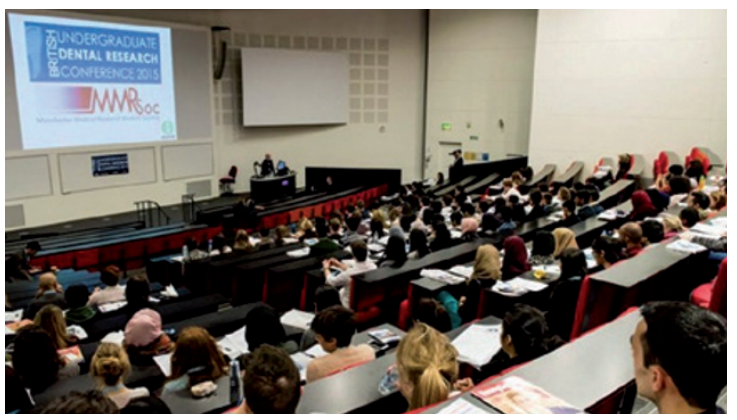

The first British Undergraduate Dental Research Conference took place on 7 March 2015 at Manchester's University Place. Two hundred and fifty students from around the UK attended the event, which was organised by Year 4 BDS students Mohammad Jaberansari, Sameera Mukadam, Rajen Nagar, and Year 2 student, Ismail Khalil.

The successful day featured research talks from world-renowned professors, including Paul Coulthard, Iain Pretty, Kevin 0'Brien and Helen Worthington. Attendees also had the opportunity to participate in separate interactive workshops. Such classes included a composite masterclass, a suturing workshop and a BDS \& Beyond presentation. The impressive turn out and enthusiasm of the conference directors, sponsors, attendees and speakers alike resulted in a great day. Following the success of this furst research meeting, it is planned to make this an annual event. MANCHESTER UNIVERSITY
Sun shining for South

West YDG conference

The newly formed BDA South

West Young Dentists Group (YDG)

enjoyed our first one-day confer-

ence on Saturday 21 February 2015 in the beautiful city of Bristol. The sun was shining, the dental conversation was flowing and the lectures were invigorating!

The South West YDG's primary aims are to help support, encourage and provide confidence for dentists in their first ten years following qualification. Our committee consists of six practitioners, ranging from foundation dentists new to the area to the more established dentists with a wealth of experience.

I am currently working at Bristol Dental Hospital as a speciality doctor in restorative dentistry, and so was fortunate to be able to recruit six undergraduate students who helped to make the day a success. For them and other young members, the conference provided multiple opportunities to network and build new connections. It served as a platform to learn more about dentistry in the 'real world'. Throughout the day four lectures were presented with subjects ranging from advice on setting up your own private practice to the prescription of flexible dentures.

The feedback about the event (including the drinks reception!) was phenomenal; it was easy to see the passion and energy bouncing off the delegates throughout the day.
From this strong start we now look to move forward. We have already planned our next event and we are also looking to provide future informative meetings, local study groups, regular CPD sessions, problem-based learning seminars and social events with the local BDA Branch section so we can continue to learn tips and tricks from our more senior colleagues.

BY PRIYA BAHAL, BDS MFDS, BDA SOUTH WEST YOUNG DENTISTS GROUP

\section{Celebrating Diplomas in Dental \\ Postgraduate Studies}

A reception for students who had completed their Diploma in Dental Postgraduate Studies in 2012-13 and 2013-14 was held on Saturday 21 February 2015 at the Victoria Rooms, University of Bristol.

Dr Nigel Robb, the current programme director, and Mr Alasdair Miller, the previous programme director, introduced the proceedings and welcomed the continued success of the programme. Each of those successful candidates who were able to attend the event had provided a brief citation covering both professional and personal life. The number of candidates who have been awarded the Diploma in Dental Postgraduate Studies now stands at 906. We are looking forward to welcoming the 1000th diplomate in the near future.

For further information on the programme visit the website http://www. bristol.ac.uk/study/postgraduate or email buold-office@bristol.ac.uk.

\section{MUSTERING MOTIVATION}

B rian Dyson, the former President and CEO of CocaCola Enterprises, during his speech at the Georgia Tech 172nd Commencement in 1996 stated: 'Imagine life as a game in which you are juggling some five balls in the air. You name them: work, family, health, friends and spirit - and you're keeping all of these in the air.

'You will soon understand that work is a rubber ball. If you drop it, it will bounce back. But the other four balls - family, health, friends and spirit - are made of glass. If you drop one of these, they will be irrevocably scuffed, marked, nicked, damaged or even shattered. They will never be the same. You must understand that and strive for balance in your life.'

In a fast paced world, particularly in a changing professional climate there are many responsibilities to juggle. Naturally at different stages in life varying 'balls' will take priority.

Self-awareness is key to finding your own balance. With a non-stop busy schedule it is very easy to overlook your needs. This has a direct effect on your well-being, interactions and patient care. Some tips to help keep those balls in the air:

1. Prioritise what is important. This is different for everyone - what do you value the most? Ask yourself what needs attention right now.

2. Ask for help. Avoid compromising patient care. Communicate with your team, friends and family.

3. Minimise activities that sap your time or energy. More time will be available to do things that 
Speciality trainees meet in Manchester

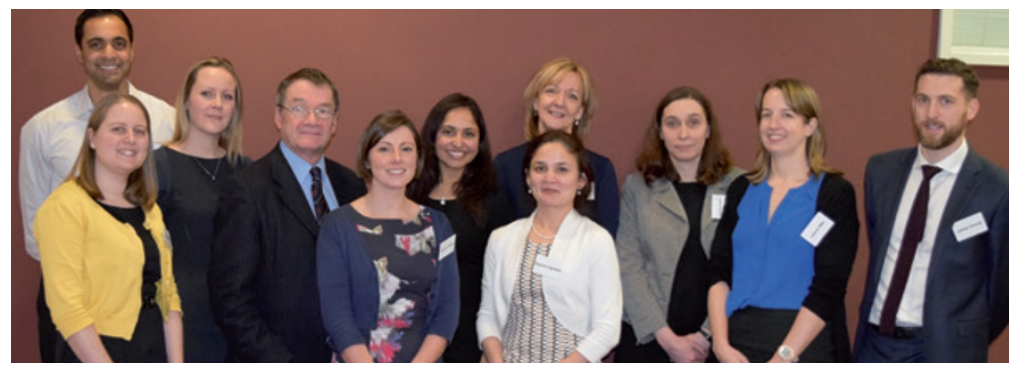

DSTNC members with speakers: (L-R) Neil Patel, Emily Sherwin, Laura Gartshore, Barry Cockroft (speaker), Monica Padilla, Chantelle Fatania, Reshma Agrawal, Elaine Hawthorn (speaker), Jane Pierce (speaker), Joanna May and James Darcey
The recently formed Dental Specialty Trainee's National Committee (DSTNC) held its inaugural conference in the Manchester Conference Centre on 6 February 2015.

The committee was set up with the joint goals of representing the voices of all UK dental StRs and providing a means of communication between registrars from different specialties. A key objective is to organise activities that will benefit all dental specialty trainees, focusing on areas common to our curricula and training needs. A first step towards achieving these goals and to raise awareness of the committee was the organisation of this national meeting.

After an introduction from the current DSTNC chair, Chantelle Fatania, the morning's session was presented by Dr Jane Povey of the Faculty of Medical Leadership and Management. She gave a varied and thought-provoking presentation which highlighted the importance of strong leadership in healthcare. She provided us all with food for thought and parted with the quote: 'Good leaders create followers, great leaders create leaders'.
The afternoon session began with a presentation from Barry Cockroft, outgoing Chief Dental Officer, covering the changing dental health demographics of our UK population.

Other presenters included Elaine Hawthorne, practice owner and chair of the Greater Manchester and Lancashire LPN for dentistry, and Jane Pierce, Head of Education, Policy and Quality Assurance at the GDC.

Our last speaker of the day was John Milne, Chair of the BDA's Dental Practice Committee. As well as demonstrating the support the BDA can provide for all the challenges with managing the evolving NHS dental system.

Feedback on the day has been positive and the committee is now looking at how we can proceed in our goals to represent trainees and provide further valuable meetings in the future.

BY MONICA PADILLA, POST-CCST STR IN ORTHODONTICS, LEEDS DENTAL INSTITUTE dental specialists, John discussed

re-energise you.

4. A little relaxation goes a long way. Build activities into your schedule that are important to you. Spend an hour a week doing something that you enjoy.

5. Act. Action will make all the difference.

\section{BY SURINDER POONIAN}

If you are a young dentist and have ideas for a story or feature for the Young Dentists section of BDJ Upfront, please contactus atbdjnews@nature.com.

\section{ELECTIONS TO THE COUNTRY COUNCILS OF THE BRITISH DENTAL ASSOCIATION}

Nominations are sought for by-elections to fill vacant seats on the following Country Councils of the British Dental Association (BDA):

\section{NORTHERN IRELAND}

- 1 vacancy representing Northern Ireland branch

\section{SCOTLAND}

- 2 vacancies representing East of Scotland Branch

- 1 vacancy representing North of Scotland Branch

- 1 vacancy representing West of Scotland Branch

\section{WALES}

- 1 vacancy representing Cardiff and South East Wales Section

- 1 vacancy representing North Wales Section

Each Country Council has the following remit:

- to provide regular advice and comment to the Principal Executive Committee as consultative committees

- to consider and advise the Principal Executive Committee on all matters relating to dentistry within the country concerned

- to advise the Principal Executive Committee on all aspects of policy within the country concerned, facilitating external expert and member input to policy formation where required

- to receive regular reports from the Principal Executive Committee, to enable each Country Council to debate and comment on the activities of the Principal Executive Committee

- to liaise with branches and sections.

Members are elected from the branches in each country or, in the case of Wales, sections. The Country Councils play a vital role in ensuring that the Principal Executive Committee, which is concerned with the strategic direction and governance of the Association, is kept in touch with the views and concerns of members. Country Council members are the 'voice of members' to the Principal Executive Committee and senior management team.

The Country Councils together constitute the United Kingdom Council which, amongst other functions, considers an annual report from the Principal Executive Committee on its strategic priorities and activities.

Term of office: This shall be until February 2018, with the entitlement to stand for a further three year term of office at that point.

More information about the by-elections to the Country Councils, including downloadable nomination forms, can be found at: bda.org/elections

Nomination forms must be returned to the Elections Team at 64 Wimpole Street, London, W1G 8YS or elections@bda.org by 17.00 Wednesday 20 May 2015. Hard copy election packs can also be obtained by contacting Stephen Skelton on 02075634141 or email s.skelton@bda.org. 